\title{
Correlates of mental health on online distance learning during COVID-19 among Malaysia vocational students
}

\author{
Wan Nurlisa Wan Ahmad ${ }^{1}$, Alea' Aqilah Idrus ${ }^{1}$, Mohamed Nor Azhari Azman ${ }^{1}$, \\ Gulzhaina K. Kassymova ${ }^{2}$ \\ ${ }^{1}$ Department of Engineering Technology, Faculty of Technical and Vocational, Universiti Pendidikan Sultan Idris, Perak, Malaysia \\ ${ }^{2}$ Institute of Metallurgy and Ore Beneficiation, Satbayev University, Almaty, Kazakhstan
}

\begin{abstract}
Article Info
Article history:

Received Jul 3, 2021

Revised Nov 15, 2021

Accepted Nov 29, 2021

\section{Keywords:}

Mental health

Online distance learning

Teaching and learning

Vocational education

ABSTRACT

The declaration of the movement control order (MCO) in Malaysia has led to the closure of the education sector due to pandemic coronavirus disease 2019 (COVID-19). The teaching and learning (T\&L) structure shifted from conventional classroom education to fully online distance learning (ODL). The unprecedented experience of 'home quarantine' has multifaced impacts on students' mental health. The study aimed to obtain the correlation of technical and vocational education and training (TVET) students' depression, anxiety, and stress (DAS) in fully implementing online distance learning. A survey study was used using a quantitative approach and respondent was evaluated by the depression anxiety stress scale-21 (DASS-21). Understudy's t-test and one-way analysis of variance (ANOVA) were utilized to investigate the relationship between these perspectives. Analysis from the DASS-21 inventory revealed that $30 \%$ had severe or extremely severe depression, $41 \%$ anxiety, and $20 \%$ stress among the vocational students. Anxiety showed a hugely significant difference among genders and the department compared to depression and stress. Therefore, the finding suggests that some intervention must ensure online distance learning is conveniently accessible and congenial with practical work for the vocational student syllabus.
\end{abstract}

This is an open access article under the CC BY-SA license.

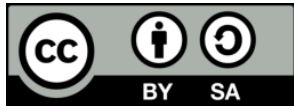

\section{Corresponding Author:}

Wan Nurlisa Wan Ahmad

Department of Engineering Technology, Faculty of Technical and Vocational, Universiti Pendidikan Sultan Idris

Tanjong Malim, Perak, 35900, Malaysia

Email: nurlisa@ftv.upsi.edu.my

\section{INTRODUCTION}

A terrible pandemic coronavirus disease 2019 (COVID-19) has increased the risk of infectionrelated death and lead to insufferable psychological in people's mental health. The continuous spread of this pandemic has compelled all education sectors to lockdown. Both teaching and learning activity was shifted from conventional physical class to online learning mode. Currently, online learning has become a robust education platform after the COVID-19 pandemic hit the world. Online learning substitutes traditional teaching and learning in a glance of the eyes and replaces virtual face-to-face learning without any physical interaction or communication between teacher and student. This digital platform is categorized as the most appropriate education option since it accommodates various applications such as WhatsApp, Telegram, Google Classroom, Padlet, Zoom, WebEx, YouTube, and Facebook Group for teaching and learning tools. Even though multiple digital education platforms were introduced, teachers should choose an appropriate platform to ensure the students' acceptance and understanding are well obtained [1]. 
Howbeit, a sudden implementation of online learning brings confusion to students and teachers. Santos et al. [2] figured out that some educational institutions have inadequate teacher preparedness to deliver skills and utilize online teaching tools and mediums. Coinciding with students' acceptance, they were confused and unprepared to cope with this unexpected situation. These actions had substantially impacted the students' mental health and could be more vulnerable in their academic performance due to this pandemic's impact [3]. The rapid changes in teaching and learning modes forced students to face many stressful events to cope with the current situation. As all education systems shifted to a fully online class, it is classified as the next higher education system that forced students and teachers to adapt to this new norm on concise notice [4]. Previous research indicates that students in secondary and tertiary education systems faced a vast range of ongoing mental health issues related to academic requirements before the outbreak. Academic pressure was the most common cause of depression, anxiety, and stress due to student's lifestyles, family background, physical and psychological health issues [5]. Saade et al. [6] found that the uneasiness when facing online courses or examination experiencing anxieties toward students' learning environment leads to poor results.

The education level in Malaysia is divided into kindergarten, primary, secondary, and higher education, also known as college or university. Technical and vocational training (TVET) involved a formal, non-formal, and informal education, starting from secondary to higher education. TVET education aims to educate students to work independently as skilled students in actual practice after graduation. Consequently, TVET education emphasizes both technical knowledge and practical assessment in the syllabus. Due to both requirements, TVET students experienced more strenuous and challenging to complete their practical syllabus for assignments, projects, and practical assessment during this time of crisis. However, most previous studies focus on the mental health effect among students in general courses, including medical, language, science, and mathematics courses fully implemented on knowledge or theory-based only. It indicates a necessity for TVET students to be studied in terms of mental health during this outbreak. It must face the new "norm" during this outbreak when the TVET students definitely do not obtain physical experiences, such as practical labs, in-person machine handling, skills training, or on-site practical experience. Indirectly, this situation will impact students' mental health because of the current learning method. Arima et al. [7] explained that teachers should know that their students' poor performance is not always due to the lack of ability but adequate access to appropriate facilities and resources while doing practical work at home.

COVID-19 has disrupted society's social norms in online education, even though the digital revolution in the educational system began long before the pandemic. A comprehensive study by Mohalik and Sahoo [8] notified that most online learning methods did not achieve the quality standard as the previous traditional learning mode. Students required some space and time to cope with the current situation. The sudden changes in the online learning method make students feel unfamiliar and unprepared mentally and physically [9]. Consequently, the terrible pandemic has brought the risk of erratic psychological emotion that affects student mental health. The wavering educational dilemma in coping with the COVID-19 pandemic needs to be taken seriously for student mental health due to inconsistent academic performance [10]. In general, everyone has experienced these natural feelings of depression, anxiety, and stress towards themselves. However, mental health could be at high risk without any limitation index from the mental health standard [11]. Researchers in China discovered a link between mental health problems and academic performance in the study population [12]. On the other hand, a study in India discovered an inverted relationship between mental health and media disclosure since the education system shifted to online classes [13].

However, one must realize that not all students are adept at using the latest technology tools in online education [14]. Some of them fear using it, and not all courses are suitable for this online education adoption, especially in practical-based education such as the TVET course. TVET is an education and training that delivers broad-based technical knowledge and skills or practical assessment in the academic syllabus [15]. Student struggles to accommodate in doing practical work at home with adequate access to appropriate facilities and resources. Furthermore, the vocational students face multiple challenges when doing their training and practical assessment without any physical contact due to social distancingcompleting the practical assessment through online mode during this pandemic negatively affected student mental health and academic performance. Students from rural areas and disadvantaged groups are more likely to suffer during online learning. They may not utilize high-speed internet access and the necessary extra technical equipment, bridging the gap between privileged and disadvantaged students. The studentfacing affected anxiety and depression and negatively affected their daily life balance. It will provoke a startling response from students, affecting mental health and anxiety [16]. Therefore, COVID-19 pandemic appears to have a detrimental impact on student's mental health when students start to refuse or are unwilling to join online classes [17].

Furthermore, the mental health of undergraduate university students should be surveillance since the pandemic brings infection and unendurable psychological pressure. Consequently, this study aims to discover

Correlates of mental health on online distance learning during COVID-19 ... (Wan Nurlisa Wan Ahmad) 
the correlation of DAS among vocational students during online learning throughout this pandemic outbreak crisis. In addition, differences between perceived mental health by gender, years of study, and course of study were also identified. Therefore, four research hypotheses were developed to guide this study, postulated, and tested at alpha level 0.05. The research hypothesis are i) H1: TVET student predominance levels of Depression, Anxiety, and stress (DAS) will not be significantly high due to online distance learning (ODL), ii) H2: There is no significant discrepancy in the DAS levels of male and female TVET students throughout the ODL session, iii) H3: The DAS level of TVET students will be influenced significantly by their years of study (semester) during ODL, and iv) H4: There is no significant discrepancy in the DAS levels for ODL activity among Engineering technology department, Agriculture science department, and Family \& consumer science department TVET students.

\section{RESEARCH METHOD}

A descriptive survey design using a quantitative approach was carried out in this study. The closure of all education sectors was due to the movement control order (MCO) announced by the Malaysian Government. The researcher assessed the mental health of these samples by using structured questionnaires through google form as an online survey method. It seemed appropriate towards the current situation. The respondents were given a link to the questionnaire in a google form set. To ensure the target respondent's data, only the person with the provided linkable answered the questionnaire. The respondents were simply briefed on the research's purpose and methodology stated on the first page of the questionnaire. Respondents were then informed that they had the option of declining to participate in the study, as this research is entirely for those voluntary to join. A simple consent form was provided for respondents to fulfil the ethical demand in answering the questionnaire. Thus, the confidentiality of the information provided by the respondents was ensured.

The completion of the survey was taken approximately five minutes. They were briefed that there were no right or wrong responses. The study was conducted at Sultan Idris Education University (UPSI) Perak, Malaysia and the data were collected in five months, from January 2021 to May 2021. A total of 252 students from Faculty Technical and Vocational were chosen as a study sample. The study's target population comprised undergraduates from semester six and the final year students involved with fully online learning throughout the semester. A sample of the target population's respondents was taken by purposive sampling. Finally, the final analysis included 152 respondents who completed the questionnaires. The response rate is $60.3 \%$.

\section{RESULTS}

\subsection{Respondents' demographics information}

Table 1 shows the summarised results for the demographic part. The obtained data were exported from Google Form to an Excell Spreadsheet and transferred to SPSS V26 for Window statistical software package. The data was analyzed on both descriptive and inferential methods.

Table 1. Demographics of the respondents $(n=152)$

\begin{tabular}{|c|c|c|c|c|}
\hline Variable & Categories & Frequency $(f)$ & Percentage $(\%)$ & Cum. Percent \\
\hline \multirow[t]{2}{*}{ Gender } & Male & 51 & 33.6 & 33.6 \\
\hline & Female & 101 & 66.4 & 100.0 \\
\hline \multirow[t]{3}{*}{ Race } & Malay & 140 & 92.1 & 92.1 \\
\hline & Chinese & 1 & 0.7 & 92.8 \\
\hline & Others & 11 & 7.2 & 100.0 \\
\hline \multirow[t]{2}{*}{ Semester } & Semester 6 & 63 & 41.1 & 41.1 \\
\hline & Semester 7 & 89 & 58.6 & 100.0 \\
\hline \multirow[t]{3}{*}{ Department } & Engineering technology & 72 & 47.4 & 47.4 \\
\hline & Agricultural science & 44 & 28.9 & 86.3 \\
\hline & Family \& consumer science & 36 & 23.7 & 100.0 \\
\hline \multirow[t]{5}{*}{ Current grade } & $4.00-3.75$ & 57 & 37.5 & 37.5 \\
\hline & $3.50-3.00$ & 88 & 57.9 & 95.4 \\
\hline & $2.75-2.50$ & 7 & 4.6 & 100.0 \\
\hline & $2.00-1.75$ & N/A & N/A & - \\
\hline & $1.50-1.00$ & N/A & N/A & - \\
\hline
\end{tabular}

Descriptive statistical analyses were used to describe the demographics section to determine the frequencies, score mean, and standard deviation to describe the sample for the demographics section. Second, 
inferential statistics used an independent T-test and ANOVA to compare the students' mean scores in semester six and final year students. Finally, inferential analysis is used to identify the relationship between the study constructs. A priori, the statistical significance level was fixed at $p=0.05$. The total number of responses was 152, and five variables have been collected include gender, race, semester of study, department in faculty technical and vocational and the current grade point average (CGPA).

\subsection{The status of mental health during COVID-19}

Figure 1 indicates the scoring DAS 21 ranks for each respondent's dealing with DAS levels. The study classified each variable as normal, mild, moderate, severe, or extremely severe. The indicator for extremely severe is in green colour and blue colour for severe. Anxiety indicated the highest percentage, with $41 \%$ of respondents facing anxiety in extremely severe and severe categories. Items 2 in anxiety variables indicated 18.4\%, 28 respondents choose extremely severe, and 23\%, 35 respondents choose severe. Detailing question for item 2 is "In the previous month, I was aware of dryness of my mouth". While Item 15 indicated $30.3 \%$ for both extremely severe and severe, the detailing question is "During semester begin, I felt I was close to panic". Both symptoms of mouth dryness and easy to become panic are signs of anxiety that students should not take for granted when dealing with mental health problems.

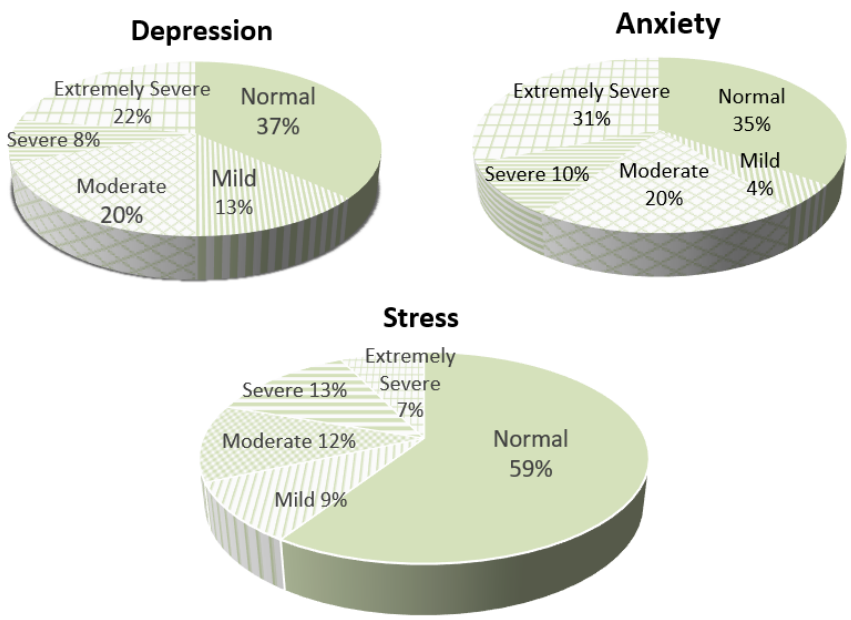

Figure 1. The proportion of respondents whose answer on the DASS 21 instrument

Regarding the mean score interpretation, DASS-21 items had a low level of agreement with the construct $(\mathrm{M}=1.05, \mathrm{SD}=0.781)$, strongly in the range disagree mean score interpretation. In this analysis, the Cronbach's coefficients alpha varied from 0.93 to 0.95 , indicating solid internal reliability of DASS measurements for a sample size $(n=152)$.

\subsection{Hypothesis 1}

TVET student predominance levels of DAS will not be significantly high due to ODL. Table 2 depicts the one-sample t-test analysis of the formulated hypothesis. The result revealed that the quantitative data analysis discovered statistically low significant predominance levels of DAS among TVET students.

Table 2. Population with one-sample t-test analysis of TVET student's predominance levels of DAS

\begin{tabular}{lccccccc}
\hline \multicolumn{1}{c}{ Variable } & Sample & Mean & Sample SD & Test value & $\mathrm{T}$ & $\mathrm{p}$-value & Cronbach alpha \\
\hline Depression & 152 & 1.10 & 0.84 & 9 & -115.72 & $<.001$ & 0.95 \\
Anxiety & 152 & 0.99 & 0.80 & 7 & -92.81 & $<.001$ & 095 \\
Stress & 152 & 1.06 & 0.79 & 14 & -201.18 & $<.001$ & 0.93 \\
\hline
\end{tabular}

Thus, the first null hypothesis in this study was failed to reject. This implies that the predominance levels of those mental health variables among TVET students are significantly low. A growing body of evidence indicates that DAS has significant negative-t values and that the reference test results were significantly greater than the sample means of the test values. The distributions of the DAS predominance levels are based on the scale classification criterion.

Correlates of mental health on online distance learning during COVID-19 ... (Wan Nurlisa Wan Ahmad) 


\subsection{Hypothesis 2}

There is no significant discrepancy in the DAS levels of male and female TVET students throughout the ODL session. Table 3 presents the independent t-test analysis of the formulated hypothesis above. The table revealed a non-statistically significant difference in the levels of DAS of both gender TVET students. Embarking with variables of mental health, which are depression and stress, there was no significant difference in the scores of male and female TVET students. However, the result for anxiety is contradict, there was a significant difference in the scores of male students $(\mathrm{M}=0.798, \mathrm{SD}=0.674)$ compared to female student $(\mathrm{M}=1.096, \mathrm{SD}=0.839 ; \mathrm{t}(150)=4.350, \mathrm{p}=0.039)$. The magnitude difference in the means (mean difference $=-0.298,95 \% \mathrm{CL}=-0.565$ to -0.306 ) was minimal with eta squared $=0.29$. Thus, most TVET students felt anxious throughout the semester when facing online distance learning due to this pandemic COVID-19 outbreak.

Table 3. An independent t-test on a discrepancy in the DAS level of TVET student's gender

\begin{tabular}{clcccccc}
\hline Variables & Gender & Sample & Mean & Std. Deviation & DF & T & p-value \\
\hline Depression & Male & 51 & 0.96 & 0.82 & 150 & 0.05 & 0.82 \\
& Female & 101 & 1.17 & 0.85 & & & \\
Anxiety & Male & 51 & 0.80 & 0.67 & 150 & 4.35 & 0.04 \\
& Female & 101 & 1.10 & 0.84 & & & \\
Stress & Male & 51 & 0.87 & 0.76 & 150 & 0.48 & 0.49 \\
& Female & 101 & 1.15 & 0.79 & & & \\
\hline
\end{tabular}

\subsection{Hypothesis 3}

The DAS level of TVET students will not be influenced significantly by their years of study (semester) during ODL. Table 4 showed a non-statistically significant difference in DAS levels for the semester among TVET students. There is no significant difference in DAS scores between semester 6 and semester 7, which is the final year semester among TVET students. Overall, the result concludes that the third null hypothesis is supported.

Table 4. An independent t-test of influence of years of study (semester) on DAS levels

\begin{tabular}{lccccccc}
\hline Variables & Semester & Sample & Mean & Std. Dev. & DF & T & p-value \\
\hline Depression & 6 & 63 & 0.932 & 0.825 & 150 & 0.322 & 0.571 \\
& 7 & 89 & 1.210 & 0.840 & & & \\
Anxiety & 6 & 63 & 0.896 & 0.801 & 150 & 0.019 & 0.889 \\
& 7 & 89 & 1.067 & 0.792 & & & \\
Stress & 6 & 63 & 0.916 & 0.786 & 150 & 0.006 & 0.937 \\
& 7 & 89 & 1.154 & 0.788 & & & \\
\hline
\end{tabular}

\subsection{Hypothesis 4}

There is no significant discrepancy in the DAS levels for ODL activity among Engineering technology department, Agriculture science department, and Family \& consumer science department TVET students. Table 5 presents the one-way ANOVA analysis of the formulated hypothesis.

Table 5. One-way ANOVA for the department (course) on DAS levels

\begin{tabular}{|c|c|c|c|c|c|c|}
\hline \multicolumn{2}{|c|}{ Source of variance } & Sum of squares & df & Mean square & $\mathrm{F}$ & Sig. \\
\hline \multicolumn{2}{|c|}{ DepressionBetween groups } & 1.581 & 2 & 0.790 & \multirow[t]{3}{*}{1.116} & \multirow[t]{3}{*}{0.330} \\
\hline & Within groups & 105.519 & 149 & 0.708 & & \\
\hline & Total & 107.100 & 151 & & & \\
\hline \multirow[t]{3}{*}{ Anxiety } & Between groups & 0.149 & 2 & 0.074 & \multirow[t]{3}{*}{0.116} & \multirow[t]{3}{*}{0.891} \\
\hline & Within groups & 95.890 & 149 & 0.644 & & \\
\hline & Total & 96.039 & 151 & & & \\
\hline \multirow[t]{3}{*}{ Stress } & Between groups & 0.894 & 2 & 0.447 & \multirow[t]{3}{*}{0.708} & \multirow[t]{3}{*}{0.494} \\
\hline & Within groups & 94.128 & 149 & 0.632 & & \\
\hline & Total & 95.022 & 151 & & & \\
\hline
\end{tabular}

The results reported no significant difference among those three departments as it relates to DAS. Depression means score based on department shows that Agricultural science department $(\mathrm{M}=1.166$ and 
$\mathrm{SD}=0.842$ ) has a higher mean score than other departments. Next, the anxiety means score indicates that Engineering technology department $(\mathrm{M}=1.026$ and $\mathrm{SD}=0.803)$ has a higher mean score than the rest of the department. Lastly, the stress variable means score revealed that Agricultural science department $(\mathrm{M}=1.120$ and $\mathrm{SD}=0.822$ ) had higher stress mean score than others. In total, this result revealed that Depression $(\mathrm{M}=1.095$ and $\mathrm{SD}=0.842)$ was reported as the most prevalent problem mean score for the department.

\section{DISCUSSION}

This empirical study examined the predominance of mental health variables among the TVET students in the Faculty of Technical and Vocational (FTV) at Sultan Idris Education University. The primary finding of this study's first hypothesis indicated that the predominance levels of those mental health variables were low among the respondents, which is less than $50 \%$ for all DAS variables. There is low and moderate knowledge regarding mental health's impact on academic performance due to COVID-19 [18]. The findings in relation to the second hypothesis indicated significant differences in anxiety while depression and stress were not significant among the TVET students. Relatively, 54 (34\%) of the TVET students indicated mild to severe depression symptoms, $72(47 \%)$ reported mild to extremely severe anxiety symptoms, and only 23 (14\%) reported mild to moderate stress. These findings are consistent with similar studies conducted among college students in the United Kingdom [17]. In addition, researchers [19] explained that mental health seems vulnerable to college students even before this pandemic outbreak happened. This finding aligns with Abdallah and Gabr [20], who found that females were more vulnerable to anxiety than males (55\% vs $45 \%$ ) due to higher self-expectations and a sense of incompetence.

The third findings concerning the hypothesis examined no statistically significant difference in DAS between the departments of technical and vocational faculty. The finding of this research is in line with Shamsuddin et al. [21] research findings, who discovered no link between the course background and depression, anxiety, or stress. This research finding, on the other hand, contradicts previous findings. Astutik et al. [22] revealed that course background was significantly related to those mental health variables. The Aquaculture study programme recorded the highest anxiety $(f=52.5 \%)$, Public health $(f=50 \%)$, and Veterinary medicine $(f=48.3 \%)$. Students in aquaculture required more credits hour in practical assessment compared to public health and veterinary medicine. Lastly, the findings of the fourth hypothesis indicated that the years (semester) had no statistically significant impact on their DAS levels. This is not surprising, given that the entire sample of responders had previously been found to have low levels of DAS, possibly due to their exposure and maturity throughout 6 and 7 semesters in University life. The findings revealed that generally, anxiety is the most prevalent issue with the highest percentage, followed by depression and stress. Thus, the results reported DAS's substantial prevalence and severity as psychological comorbidities among TVET students in UPSI, Malaysia. These findings are consistent with those of many earlier studies in China [12], Japan [7], Indonesia [23] and other countries that were investigating college and university student mental health in various fields of study.

\subsection{Implementation and strategy to protect mental health during the COVID-19 pandemic}

The COVID-19 outbreak has impacted Malaysia's political, economic, social, health, safety, religious, and educational sectors. Even educational institutions, as well as internal components of psychology and student well-being, are affected. Students' mental health is crucial in determining their self-sufficiency in the online learning process [24]. Since March 25, 2020, the Ministry of Health Malaysia [25] reports that the psychosocial support assistance line has received 122,328 calls. Of these, 109,806 calls $(89.4 \%)$ were closely related to the psychological issues of the consequent from the COVID-19 pandemic outbreak. The majority of callers seek emotional support as well as counselling. Thus, educators need to deal with the issue prudently in addressing the increasing number of mental health problems among students, especially university students. Every educator must take proactive steps to ensure that no student falls behind during the teaching and learning process and that the primary goals of holistic and inclusive learning are encountered.

In addition, government bodies and Non-Government Organisations (NGOs) need to provide mental support through unique lines or links outside the university as available assistance to students. Information on mental health needs to be improved, diversification of movement systems for mental health assistance and support must be equivalent and provided comprehensively [26]. First, students who seek help are promised confidential information will be guaranteed. Second, the mechanism for getting help should be simplified so that individuals feel that if they need help, it is not complicated. Easy to get an appointment (for physical support assistance) or face-to-face discussion (phone line, email, text message or voice/video internet calls). The presentation should be made in graphic form as a facilitator, and the presentation can be made through university forums and social media. An open discussion needs to occur, and the main essence needs to touch on getting help. In addition, the information presented should educate university residents that mental health is essential and problems such as mental and emotional stress are common and expected. They also need to

Correlates of mental health on online distance learning during COVID-19 ... (Wan Nurlisa Wan Ahmad) 
be aware that counselling and consultation sessions can treat them healthy, especially if help and support are given early.

Saha et al. [27] described that healthcare providers, policymakers, decision-makers, and responsibilities are challenging to improve the education systems. Students, especially final year vocational students, need to complete final year projects and undergo industrial training, face to face online learning and complete assignments that will be assessed according to the previous criteria before the pandemic begins. Therefore, there is a need to consider educational policies towards a new norm in education. According to the current situation, education policy should follow the learning syllabus not to be marginalized from the learning process. Universities should consider implementing systematic and continuous online distance learning to adapt to this new norm condition. Collaboration and sharing sessions of information between lecturers and students' feedback could improve student mental health. Collaboration between higher education institutions and local healthcare services is required to regularly refer severe cases for treatment and help students learn about mental health management.

\subsection{Limitation}

Some limitations of this study should be noted. First, as the COVID-19 impact is still unfolding, we collected data and conducted the analysis. More complete data could emerge with rigorous data over a more extended period. Second, the study has been collected the data from online form an approach that is subject to methodological biases in selection and response bias on the prevalence of mental health problems seen in this sample. We were careful to ensure that the participant's recruitment focused on technical and vocational students who take fully online distance learning at home. Responding to this limitation, future research is recommended to employ a longitudinal approach as well as qualitative methods such as interviews session and focus groups on perceiving further the impacts of pandemic information exposure on TVET students' psychological well-being. Notably, our study used both languages in English for DASS-21 and Bahasa Melayu version for the informed consent form. Finally, the study is constrained by the restricted number of responses in the last two semesters. Then, the outcome should then be explained with caution. Despite these limitations, our findings and results are consistent with those of other studies.

\section{CONCLUSION}

The current study addressed that online distance learning during the COVID-19 Pandemic. On average, online distance learning has not been effective for TVET student mental health. From the research results, students are facing high levels of anxiety with online learning amid this outbreak. In other words, the previous conventional learning method is still dominant and preferable to student acceptance. As a result, students feel anxious for every class activity and worry about missing the learning session. These negative emotional symptoms result in a lack of psychological well-being, which interferes with the learning process and limits these students' academic performance. Besides that, mental health negatively impacts student motivation and interest, resulting in poor health conditions such as headaches and fatigue. Therefore, early detection of students under poor mental health is crucial in enhancing academic performance, especially during online distance learning. Thus, some interventions or monitoring are needed to improve the psychological health of TVET students who will assist in nurturing the country's health care workers. The study's findings will be helpful for all the stakeholders of the educational system that are currently moving toward e-learning during the crisis. The study emphasizes the mental health factors that are critical to student acceptance in online distance learning.

We acknowledge that the analysis of the data presented herein is too early to draw any conclusions. However, the goal of this study is to look into the possibility of further analysis and research in mental health for technical and vocational students. Nevertheless, this study answers whether DAS exists in an online distance learning context and points to current significant views towards TVET students.

\section{REFERENCES}

[1] A. Azis and Mustiningsih, "The phenomenon of online learning in educational institutions during the COVID-19 pandemic," Proceedings of the 1 st International Conference on Information Technology and Education (ICITE 2020), 2020, doi: 10.2991/assehr.k.201214.268.

[2] J. Santos, L. F. De Jesus, R. R. Sealmoy, and R. R. C. Fajardo, "Online distance learning amidst COVID-19," IJERI: International Journal of Educational Research and Innovation, no. 15, pp. 291-304, Dec. 2020, doi: 10.46661/ijeri.5271.

[3] A. Perveen, H. Hamzah, F. Ramlee, A. Othman, and M. Minhad, "Mental health and coping response among Malaysian adults during COVID-19 pandemic movement control order," Journal of Critical Reviews, vol. 7, no. 18, pp. 653 LP - 660, 2020

[4] S. Sancili and M. N. Tugluk, "Investigation of the problem behaviors emerging in children during the COVID-19 pandemic," Southeast Asia Early Childhood Journal, vol. 10, no. 1, pp. 101-116, 2021

[5] N. I. C. Zulkifli and N. F. Mohammed, "A Study of relationship between mental health and smoking among adolescences in

Int J Public Health Sci, Vol. 11, No. 1, March 2022: 254-262 
Tanjong Malim District," Jurnal Pendidikan Bitara UPSI, vol. 13, no. 2, pp. 48-57, 2020, doi: 10.37134/bitara.vol13.2.5.2020

[6] R. George Saadé, D. Kira, T. Mak, and F. Nebebe, "Anxiety \& performance in online learning," in Proceedings of the 2017 InSITE Conference, 2017, pp. 147-157, doi: 10.28945/3736.

[7] M. Arima, Y. Takamiya, A. Furuta, K. Siriratsivawong, S. Tsuchiya, and M. Izumi, "Factors associated with the mental health status of medical students during the COVID-19 pandemic: a cross-sectional study in Japan," BMJ Open, vol. 10, no. 12, p. e043728, Dec. 2020, doi: 10.1136/bmjopen-2020-043728.

[8] R. Mohalik and S. Sahoo, "E-radiness and perception of student teachers' towards online learning in the midst of COVID-19 pandemic," SSRN Electronic Journal, 2020, doi: 10.2139/ssrn.3666914.

[9] R. I. Sifat, "COVID-19 pandemic: Mental stress, depression, anxiety among the university students in Bangladesh," International Journal of Social Psychiatry, vol. 67, no. 5, pp. 609-610, Aug. 2021, doi: 10.1177/0020764020965995.

[10] M. Akhtarul Islam, S. D. Barna, H. Raihan, M. Nafiul Alam Khan, and M. Tanvir Hossain, "Depression and anxiety among university students during the COVID-19 pandemic in Bangladesh: A web-based cross-sectional survey," PLOS ONE, vol. 15, no. 8 August, p. e0238162, Aug. 2020, doi: 10.1371/journal.pone.0238162.

[11] R. A. Hasni, S. Kram, E. Waqqash, and M. Chan, "Competitive anxiety among university student-Athlete of Uitm Sarawak," Jurnal Sains Sukan dan Pendidikan Jasmani, vol. 10, no. 1, pp. 7-14, 2021, doi: 10.37134/jsspj.vol10.1.2.2021.

[12] W. Cao et al., "The psychological impact of the COVID-19 epidemic on college students in China," Psychiatry Research, vol. 287, May 2020, doi: 10.1016/j.psychres.2020.112934.

[13] S. K. Chaturvedi, "COVID-19, coronavirus and mental health rehabilitation at times of crisis," Journal of Psychosocial Rehabilitation and Mental Health, vol. 7, no. 1, pp. 1-2, Apr. 2020, doi: 10.1007/s40737-020-00162-z.

[14] P. K. Jena, “Online learning during lockdown period for COVID-19 In India," International Journal of Multidisciplinary Educational Research (IJMER), vol. 9, no. 5 (8), 2020, doi: 10.31235/osf.io/qu38b.

[15] B. R. P. Shrestha, "Vocational education and training graduates: challenges in practical skills to the job market," International Journal of Social Sciences and Management, vol. 3, no. 3, pp. 141-145, Jul. 2016, doi: 10.3126/ijssm.v3i3.15264.

[16] M. M. Saad and A. Ahmad, "The validity and reliability of the instrument adolescent social anxiety scale (Sksr) (1 - 6)," Jurnal Pendidikan Bitara UPSI, vol. 6, no. 1, 2019.

[17] C. Woolston, "Signs of depression and anxiety soar among US graduate students during pandemic," Nature, vol. 585, no. 7823, pp. 147-148, 2020, doi: 10.1038/d41586-020-02439-6.

[18] J. M. Santiago and A. R. Santos, "Knowledge, attitude and practices of the university students about COVID-19 during the Luzon lockdown in the Philippines," International Journal of Public Health Science (IJPHS), vol. 10, no. 3, pp. 670-678, Sep. 2021, doi: 10.11591/ijphs.v10i3.20844.

[19] A. Z. A. Abd Razak, N. K. Y. Y. Yeop Yunus, N. Samsudin, H. Ab Wahid, and Z. W. Wahid, "Social support moderating effect between work-family conflict and health and stress of working students in UPSI," International Business Education Journal, vol. 12, no. 1, pp. 25-38, Nov. 2019, doi: 10.37134/ibej.vol12.3.2019.

[20] A. R. Abdallah and H. M. Gabr, "Depression, anxiety and stress among first year medical students in an Egyptian public university," International Research Journal of Medical Scince, vol. 2, no. 1, pp. 11-19, 2014.

[21] K. Shamsuddin et al., "Correlates of depression, anxiety and stress among Malaysian university students," Asian Journal of Psychiatry, vol. 6, no. 4, pp. 318-323, Aug. 2013, doi: 10.1016/j.ajp.2013.01.014.

[22] E. Astutik, S. K. Sebayang, S. I. Puspikawati, T. D. Tama, and D. M. S. K. Dewi, "Depression, anxiety, and stress among students in newly established remote university campus in Indonesia," Malaysian Journal of Medicine and Health Sciences, vol. 16, no. 1, pp. $270-277,2020$.

[23] P. Pribadi, L. Lolita, R. C. A. Pangestuti, H. Lutfiyati, S. Mareti, and A. Ikhsanudin, "Knowledge and quality of life among Indonesian students during the COVID-19 pandemic," International Journal of Public Health Science (IJPHS), vol. 10, no. 2, pp. 451-458, Jun. 2021, doi: 10.11591/ijphs.v10i2.20819.

[24] N. Samar and A. Perveen, "Relationship between mental health literacy and help seeking behavior among undergraduate students," International Journal of Academic Research in Business and Social Sciences, vol. 11, no. 6, pp. 216-230, Jun. 2021, doi: 10.6007/IJARBSS/v11-i6/10113.

[25] K. K. Malaysia, "Mental Health Psychosocial Support Services." https://covid-19.moh.gov.my/semasa-kkm/2021/06/inisiatifperkhidmatan-kesihatan-mental-dan-sokongan-psikososial-mhpss-kkm (accessed Jan. 14, 2021).

[26] R. Lathabhavan and M. Griffiths, "First case of student suicide in India due to the COVID-19 education crisis: a brief report and preventive measures," Asian Journal of Psychiatry, vol. 53, Oct. 2020, doi: 10.1016/j.ajp.2020.102202.

[27] A. Saha, A. Dutta, and R. I. Sifat, "The mental impact of digital divide due to COVID-19 pandemic induced emergency online learning at undergraduate level: Evidence from undergraduate students from Dhaka City," Journal of Affective Disorders, vol. 294, pp. 170-179, Nov. 2021, doi: 10.1016/j.jad.2021.07.045.

\section{BIOGRAPHIES OF AUTHORS}

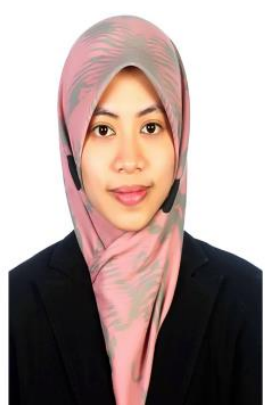

Wan Nurlisa Wan Ahmad (D) 81 SC P is a lecturer of Engineering Technology, Faculty of Technical and Vocational, Universiti Pendidikan Sultan Idris, Malaysia. She is currently pursuing $\mathrm{PhD}$ in Universiti Malaysia Pahang, Malaysia under Medical Engineering and Health Intervention Team (MedHiT). Her research interests include Biomechanical Engineering, Health Monitoring System for Wireless Sensor Networks, Internet Of Things, and Technical And Vocational Education And Training (TVET). She is interested in exploring human determinants of health and wellbeing in later life. She can be contacted at email: nurlisa@ftv.upsi.edu.my. 

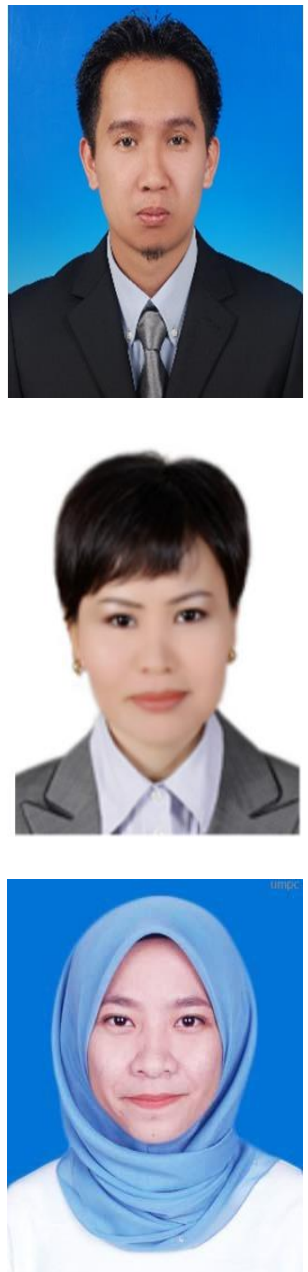

Mohamed Nor Azhari Azman (D) 8d SC P is an Associate Professor of Technical and Vocational Education, Faculty of Technical and Vocational, Universiti Pendidikan Sultan Idris, Malaysia. He is the author, co-author and editor of several books or book chapters on Industrialised Building System (IBS), STEM Education, GIS and Technical and Vocational Education and Training (TVET). He is actively involved with Construction Industry Development Board (CIDB) workshop on the IBS policy. In addition, he is also contributing his expertise in TVET and forum sharing with the Centre for Instructor and Advanced Skill Training (CIAST). Research interests focus on the study of Industrialised Building System (IBS), Precast Manufacturing Plant, Spatial Site Selection, Technical and Vocational Education and Training (TVET) \& well being. He can be contacted at email: mnazhari@ftv.upsi.edu.my.

Gulzhaina K. Kassymova (D) $S C$ P is a senior lecturer in educational psychology at Abai Kazakh National Pedagogical University and head of the department of the intellectual properties and international cooperation in the Institute of Metallurgy and Ore Beneficiation, Satbayev University in Almaty, Kazakhstan. Before, she has been a lecturer in linguistics. She has published over one hundred peer-reviewed scientific articles in major journals on the subjects of teaching, e-learning, and cognitive pedagogy. She can be contacted at email: g.kassymova@satbayev.university; Zhaina.kassym@gmail.com.

Alea Aqilah Idrus (iD 8. SC P is a final year student of a bachelor's degree in education of Design and Technology, Faculty of Technical and Vocational, Universiti Pendidikan Sultan Idris, Malaysia. Before, she had her Diploma in Business Management at Polytechnic Sultan Azlan Shah, Perak, Malaysia. Her research interest in Technical and Vocational Education (TVET) and currently. She can be contacted at email: aleaqilah@gmail.com. 